\title{
Research on Influential Factors of Tourism Consumption Behavior Based on Cross-cultural Theory
}

\author{
Zhong-Xiu HAO* \\ Tianjin Chengjian University, China \\ ahaorachel@126.com \\ ${ }^{*}$ Corresponding author
}

Keywords: Cross-cultural tourism, Influential factors, Consumption behavior.

\begin{abstract}
The cross-cultural tourism is an important international leisure market for enriching the tourism economy and prospering the tourism culture. How to effectively increase the exhibition of tourism products and enrich the tourism content remains quite challenging. In this work, the author analyzed several influential factors, including regional humanity background differences, economic differences, income differences and consumption levels. As shown in the analysis, the cross-cultural tourism, an activity with multiple dimensions (horizontal and vertical), is multi-level culture exchange and interaction, which not only affects and enriches cultural and spiritual life of the tourism subject, but also substantially decides product development and management manner of tourism.
\end{abstract}

\section{Introduction}

With the continuous improvement of internationalization, the transnational tourism has become the main consumption mode and social economic activities[1]. So far, China has strengthened economic, cultural and political exchanges with the other countries. Simultaneously, the tourism consumption has become the main economic exchange model in China. As a new economic mode, the cross-cultural tourism promotes the development of leisure consumption market internationalization, enriches the tourism economy connotation, booms the tourism culture, as well as is the important way of international cultural exchange, which possesses the huge consumer groups and tremendous development potential. In recent years, China has strongly advocated the development of cross-regional, multinational culture industry, which accelerates the integration of tourism and cultural industries, promotes the prosperity of international tourism consumption market. The fast development of the tourism industry have caused the strong competition of tourism consumption, which makes various people increasingly realize the importance and necessity for the tourism market research. Therefore, how to effectively increase the exhibition of tourism products, to enrich the tourism content and attract more foreign tourists in cross-cultural background, to understand the cultural and spiritual needs of visitors with different cultural backgrounds in consumer behavior and enhance the sense of cultural experience, have become the most important research topics for cross-cultural tourism.

For cross-regional and transnational tourism product consumption, people who possess different regional culture and experience have different insights and feelings to tourism. The tourism consumption is not only restricted by economic ability, but also influenced by many internal and external motivation factors[2]. It is very important to explore the crucial factors influencing the improvement of tourism products quality, the enhancement of the tourism consumption experience and the consumer behavior. Researchers qualitatively and quantitatively analyzed the decision-making controllable factors and the preference behavior of tourism consumption[3, 4]. Some analyzed and compared people's tourism consumption preference and tourist behavior law in different countries by using tourism geography and psychology[5]. In this paper, based on the cross-cultural theory, the author analyzes the effects of different cultural background on the purchase of tourism products and provides basic rules and trends of cross-cultural tourism product consumption. 
In addition, it can be necessary to point out that the tourism text is the important way to transfer the tourism information. The main function of the tourism publicity texts is to expand people's knowledge horizons and inspire people's interests to travel and visit the scenic spot. An ideal publicity text can attract the foreign tourists and directly promote economic development by information interaction. Therefore, it is important to integrate the culture information into the original text in order to preserve the cultural identity during the process of dissemination.

\section{Theory}

The cultural differences have become the important effect factors for tourism consumption [6], so increasingly widespread attention has been paid to the research of the impact of cross-cultural theory on tourism products consumption by tourism culture research workers. The cross-cultural tourism is also affected by the regional culture background differences, economic differences, income differences and consumption levels, etc. Tourism products embody the development of local tourism cultural information, including local customs, historical culture, and national belief and so on. By accurately extracting the important feature factors and bringing the visual and spiritual enjoyment to tourists in a relatively short period, visitors not only have a profound understanding of local culture, but also effectively realize the culture transmission by the tourism products. This requires us to appropriately deal with the cultural information contained in tourism texts. When the tourists have the across-region travelling, their previous cultural experience will have an interaction with the impact of the tourism object on them. The cross-cultural study of tourism is a science of the relationship between tourism and culture, the constitution system of tourism culture, and the formation and development law of tourism culture [7]. A cross-culture tourism perception model was built based on the study of cultural differences [8], which shows that the tourism perception is influenced by tourism subject cultural values and social interaction rules. In addition, the cultural values determine social interaction rules, and effect the tourism object perception. The above factors further determine the importance and satisfaction of the tourism. Moreover, the importance has a direct relationship with satisfaction. On the whole, the cross-cultural tourism with multiple dimensions is multi-level culture exchange and interaction. It not only affects and enriches the cultural and spiritual life of the tourism subject, but also determines the product development and management mode of the tourism object.

\section{Analysis and Discussion}

Figure 1 shows the mode of tourism consumption decision. People can access the information of tourism destinations through different channels, including internet, advertisement, and reputation. Internet is the most direct way of information transmission. The tourism texts in the internet involve all aspects of the content, including scenic spots, historical sites, customs, historical allusions, religious belief, folk customs, diet habit, geographical features and so on. The poetry and ancient prose frequently appear in tourism introduction with concise words and rich meaning. So it puts forward a high demand for this translation, which should not only conform to the expression habit of the target language, but also accurately disseminate culture connotation. As a typical cross-cultural communication activity, the tourism text translation can not only be simply defined as the transition of the two languages, but also the communication between the two different cultures. Once people have determined the destination of the trip, the primary information to be learned about the destination is the economic level, security status and attractiveness. Woodside and Dueler studied and tested the theory of tourism consumption systems [9]. The results from the research show that the tourism consumption behavior has a direct relationship with the cultural background of tourism subjects and the information accessible to tourism subjects. 


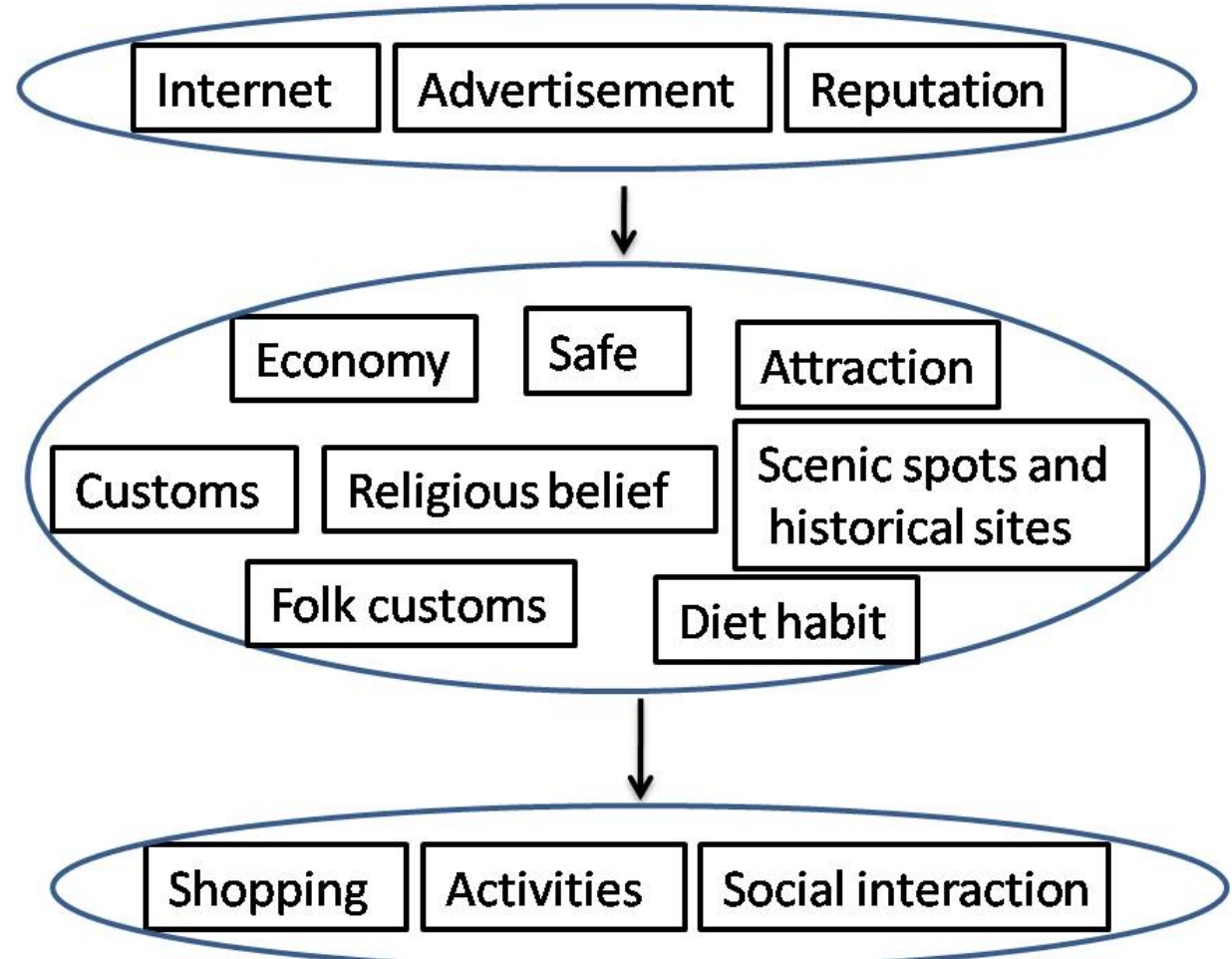

Figure. 1. The mode of tourism consumption decision.

Table 1 shows the star level of main consumption behavior factors obtained from statistical results of a social survey. The novelty displayed five star level, which can be attributed to people's curiosity about new knowledge and information [10]. From the previous theoretical research, novelty can be considered as a main factor during the process of tourism consumption. It needs to be mentioned that people's tourism activities no longer concentrate on buying souvenirs and gifts with the arrival of the era of economic globalization. The shopping can be a secondary factor with fast globalization of economy and quick development of science and technology. The number of tourists purely for the purpose of shopping is declining year by year. Because of the influence of living environment, working pressure and other factors, the number of international tourism is increasing with years. It is necessary to mention that the number of the population who has a social relationship with other tourism consumption subjects is increasing. The information could help managers and marketers better design and tailor their products.

Table 1.Factor analysis of typical tourist behaviors.

\begin{tabular}{|l|l|l|}
\hline Consumption behaviors & Star level & Trend \\
\hline Interested in novelty & $* * * * *$ & $\uparrow$ \\
\hline Feel the local culture & $* * * *$ & $\uparrow$ \\
\hline Buy gifts or souvenirs & $* * *$ & $\downarrow$ \\
\hline Release pressure & $* * *$ & $\uparrow$ \\
\hline Socialize with other tourists & $* *$ & $\uparrow$ \\
\hline
\end{tabular}




\section{Summary}

In conclusion, the tourism consumption behavior factors in cross-cultural tourism are analyzed in detail. The author analyzed several influential factors, including regional humanity background differences, economic differences, income differences and consumption levels. The cross-cultural tourism, an activity with multiple dimensions (horizontal and vertical), is multi-level culture exchange and interaction. It is meaningful for developing and tailoring new products so as to prevent the mismatch of supply and demand. We should further strengthen the research on cultural factors contained in products, which can be a practical guide to tourism products development and tourism marketing.

\section{Acknowledgement}

This research was financially supported by Tianjin Art and Science Project (2014-C14071).

\section{References}

[1] W. Enders, T. Sandler. Causality between transnational terrorism and tourism: The case of Spain. Terrorism, 14(1991):49-58.

[2] K. Borodako, J. Berbeka, M. Rudnicki. External and internal factors motivating outsourcing of business services by meeting-industry companies: a case study in Krakow, Poland. Journal of Convention \& Event Tourism, 16(2015):93-115.

[3] Dong-Ju YUE. An Empirical Analysis of Inbound Tourist Decision-making Behavior in Xi'an. Journal of Xian University of Arts \& Science, 2011(in Chinese).

[4] Si-Yi CHEN, Song LU, Ming-Zhu ZHANG, Bing-zhong GUAN. Investigaion and Research of the Preference Behavior on Rual Tourism belong to City Residents in Nanjing. East China Economic Management, 2007(in Chinese).

[5] De-Kui LI, Fan ZHOU, Han-Ping WU, Meng-Ru WANG, Xiao-Dan TONG, Research on adjustment effect of report about chinese citizens' uncivilized behaviors in outbound tourism. Journal of Green Science \& Technology., 2014. (in Chinese).

[6] M. H. Chen, S. C. Jang, Y. J. Peng, Discovering optimal tourist market mixes. Journal of Travel Research, 50(2011):602-614.

[7] T. R. Vicente, Public policies for culture and tourism the intermeshing of actions in the development of the organizations for tourism in Pernambuco EMPETUR and EMETUR. Cultur Revista De Cultura E Turismo, 2009:25-45.

[8] Y. Reisinger, L. W. Turner, Cross-cultural behaviour in tourism: concepts and analysis. Tourism \& Hospitality Research, 5(2005):372-373.

[9] A. G. Woodside, C. Dubelaar, A general theory of tourism consumption systems: a conceptual framework and an empirical exploration. Journal of Travel Research, 41(2002), 120-132.

[10] X. P. Li, X Xiang [Li R L, Hudson S. The application of generational theory to tourism consumer behavior: an American perspective.[J]. Tourism Management, 2013, 37(3):147-164. 